\title{
6-Mercaptopurine and inflammatory bowel disease: Hidden ground for the cytomegalovirus
}

\author{
LC Hookey BSc MD ${ }^{1}$, W Depew BSc MD ${ }^{1}$, A Boag BSc MSc MD², S Vanner MSc MD ${ }^{1}$
}

LC Hookey, W Depew, A Boag, S Vanner. 6-Mercaptopurine and inflammatory bowel disease: Hidden ground for the cytomegalovirus. Can J Gastroenterol 2003;17(5):319-322.

6-Mercaptopurine (6-MP) and azathioprine are important drugs for the treatment of inflammatory bowel disease (IBD) but their actions suppress host defense against infection. A challenging case of a 19-year-old female patient with quiescent Crohn's disease maintained with 6-MP presenting with dyspnea and a normal chest exam and $\mathrm{x}$-ray is presented. She became ventilator-dependent and only after numerous investigations was diagnosed with cytomegalovirus (CMV) pneumonitis. A systematic literature review of CMV infections in IBD patients was performed. The present case is the first report of a patient with quiescent IBD maintained on 6-MP who developed CMV pneumonitis. Other reports have identified patients with active disease on multiple immunosuppressants who developed CMV pneumonitis and also highlight the risk of CMV colitis in refractory IBD. The authors review the approach to the diagnosis of CMV infections in IBD patients with atypical pneumonia and colitis and highlight the importance of considering CMV infection in these settings.

Key Words: 6-mercaptopurine; Azathioprine; Crohn's disease; Cytomegalovirus; Inflammatory bowel disease

\section{La 6-mercaptopurine et les maladies inflammatoires de l'intestin : Un motif caché de cytomégalovirus}

\begin{abstract}
RÉSUMÉ : La 6-mercaptopurine (6-MP) et l'azathriopine sont des médicaments importants dans le traitement des maladies inflammatoires de l'intestin (MII), mais leur action supprime les défenses de l'hôte contre l'infection. Est décrit le cas difficile d'une femme de 19 ans atteinte d'une maladie de Crohn inactive et prenant un traitement d'entretien à la 6-MP présentant une dyspnée, mais un examen thoracique et des rayons $\mathrm{X}$ normaux. Elle a dû recevoir une ventilation assistée, et ce n'est qu'après de nombreux examens qu'on a diagnostiqué une pneumonite à cytomégalovirus (CMV). Une analyse bibliographique systématique des infections à CMV chez les personnes atteintes d'une MII a été exécutée. Ce cas est le premier à porter sur un patient atteint d'une MII inactive prenant un traitement d'entretien à la 6-MP et qui développe une pneumonite à CMV. D'autres rapports ont fait état de patients atteints d'une maladie en phase active et prenant de multiples immunosuppresseurs qui développent une pneumonite à $\mathrm{CMV}$ et soulignent le risque de colite à $\mathrm{CMV}$ en cas de MII réfractaire. Les auteurs examinent la démarche face au diagnostic d'infections à CMV chez les personnes atteintes d'une MII présentant une pneumonie et une colite atypiques et soulignent l'importance d'envisager la possibilité d'une infection à CMV dans ces circonstances.
\end{abstract}

The authors describe a challenging case of a patient presenting with life-threatening CMV pneumonitis whose Crohn's disease had been maintained in remission by a single agent, 6-MP. The case highlights the difficulties diagnosing CMV infection in this unusual setting and the discussion reviews risk factors and presentations of CMV infection in IBD and the approach to diagnosis.

\section{CASE PRESENTATION}

A 19-year-old white university student presented with a onemonth history of fever, chills, poor appetite and a progressively worse nonproductive cough.

Crohn's disease was diagnosed nine years before admission and the patient had undergone three previous laparotomies and bowel resections for stenosing Crohn's of the terminal and neoterminal ileum. Remission was induced and maintained with 6-MP (50 mg/day, $1 \mathrm{mg} / \mathrm{kg} / \mathrm{day})$ for the past 18 months. It had been started due to the severity of the patient's disease and as a steroid-sparing agent. Her leukocyte counts had been monitored on a monthly basis by her physician, and had

\footnotetext{
${ }^{1}$ Gastroenterology Diseases Research Unit; ${ }^{2}$ Department of Pathology, Queen's University, Kingston, Ontario

Correspondence: Dr Stephen J Vanner, Gastroenterology Division, Hotel Dieu Hospital, 166 Brock Street, Kingston, Ontario K7L 5G2

Telephone 613-544-3400 ext 2332, fax 613-544-3114, e-mail vanners@hdh.kari.net

Received for publication June 18, 2003. Accepted February 12, 2003
} 
remained normal. The most recent leukocyte count was performed six weeks before admission, and was completely normal.

On admission her temperature was $39.4^{\circ} \mathrm{C}$, pulse 110 beats/min and respiratory rate 16 breaths/min. Physical examination was otherwise normal. Her blood work was: leukocytes $2.6 \times 10^{9} / \mathrm{L}$, neutrophils $1.92 \times 10^{9} / \mathrm{L}$, lymphocytes $0.32 \times 10^{9} / \mathrm{L}$, hemoglobin $112 \mathrm{~g} / \mathrm{L}$ and platelets $194 \times 10^{9} / \mathrm{L}$. Chest and abdominal $\mathrm{x}$-rays were normal. A computed tomographic scan with gastrointestinal contrast was performed to rule out an occult intra-abdominal abscess. None was seen nor was there suggestion of inflammation in the neoterminal ileum. Blood, urine and sputum cultures were obtained.

On the second night of admission, the patient's respiratory status acutely deteriorated and fine crackles were heard throughout both lung fields. Her room air oxygen saturation was $73 \%$ and chest $\mathrm{x}$-ray showed a bilateral, diffuse, mixed airspace and interstitial disease pattern (Figure 1). A presumptive diagnosis of atypical pneumonia was made and she was started on a second-generation cephalosporin and a macrolide. The following day a bronchoscopy was performed to assess for opportunistic pathogens. The right bronchial system was explored and mild edema was seen. There was no purulent or hemorrhagic material. Bronchial washings were obtained and sent for bacterial culture and sensitivity, Gram stain, Pneumocystis carinii direct fluorescent antibody, potassium hydroxide stain and fungal culture, viral culture and cytology.

On day four of admission, the patient's respiratory status deteriorated further. Her respiratory rate was markedly elevated at 50 breaths/min and her pulse was 120 beats/min. One hundred per cent oxygen was required to maintain oxygen saturations above $90 \%$. She was transferred to the intensive care unit for nasal bilevel positive airway pressure therapy and closer observation. Bronchoscopy was repeated on day 6 and a transbronchial biopsy was obtained. On day 9 the transbronchial biopsy was reported to reveal cytopathic changes in the nuclei of the pneumocytes consistent with CMV (Figure 2A) and was confirmed with immunohistochemical staining (Figures 2B). The same day, cultures from the initial bronchoscopy washings were also reported to be growing CMV. Anti-CMV immunoglobulin (Ig) M or IgG were not detected in the patient's serum. No other pathogens were cultured from the specimens. Human immunodeficiency virus serology was negative.

Intravenous ganciclovir (500 mg every $12 \mathrm{~h}$ ) and immunoglobulins ( $25 \mathrm{~g} /$ day $)$ therapy were initiated. Initially, her condition worsened, and by day 11 she required intubation for respiratory failure. Her neutrophil count also decreased, with a nadir of $0.68 \times 10^{9} / \mathrm{L}$, likely secondary to the ganciclovir therapy. Granulocyte colony stimulating factor was initiated and bronchoscopy repeated on day 16 to assist in differentiating between ventilator-acquired pneumonia and acute respiratory distress syndrome. Bronchial washings failed to reveal evidence of bacterial infection and the patient was started on intravenous corticosteroids for fibroproliferative acute respiratory distress syndrome. Her respiratory status dramatically improved in the next two days, permitting extubation. Although therapy was planned to continue for 21 days, the intravenous ganciclovir was discontinued after 19 days because of an elevation of the patient's transaminases, which subsequently returned to normal. The intravenous corticosteroids were switched to oral and tapered over the next three weeks to discontinuation.

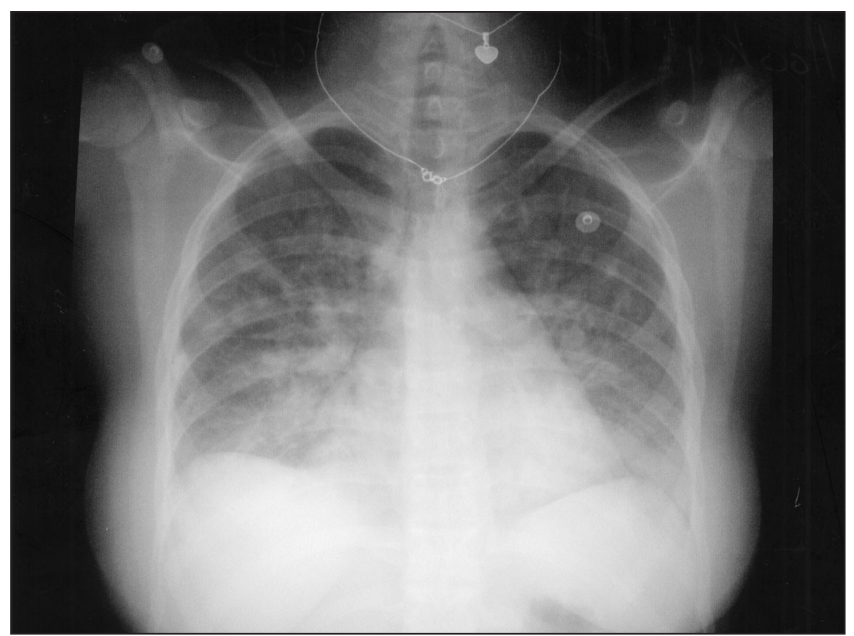

Figure 1) Posteroanterior view of a chest $x$-ray taken on the second day of admission following acute deterioration in the patient's respiratory status. Although the admission chest $x$-ray was normal, a diffuse, bilateral, mixed airspace and interstitial disease pattern is now clearly evident

The patient was discharged from hospital 33 days after admission. 6-MP has not been restarted. Regarding a possible recurrence of infection, she was educated regarding signs of infection and advised to seek medical attention earlier. Six months after discharge, the patient was doing well, off all medications and preparing to return to university.

\section{DISCUSSION}

CMV infection in IBD patients has been reported in two general clinical settings: patients presenting with extraintestinal symptoms whose IBD is in clinical remission and those presenting with a flare-up of their IBD symptoms or having refractory disease (5-9). Our patient is the first reported case with CMV pneumonitis, which developed while being maintained in remission on a single agent, 6-MP. The findings of this case have implications concerning the clinical setting in which CMV must be considered and the contribution of drugs in predisposing patients with IBD to CMV infection.

Isolated CMV infections in patients with quiescent IBD seem to be rare. Several cases of CMV pneumonitis have been reported previously, but only in the setting of multiple immunosuppresants and/or refractory disease. For example, Papadakis et al (5) reported a patient receiving multiple immunosuppressants (cyclosporine, 6-MP and steroids) and coinfected with P carinii and Nocardia. One other reported case occurred in the setting of refractory disease, with coinfection of the gastrointestinal tract (6). In contrast to the transplant literature, we did not find any reports of other isolated extraintestinal manifestations of CMV infection in IBD patients, such as meningoencephalitis, myocarditis, or thrombocytopenia and hemolytic anemia.

Recent reports suggest that CMV intestinal infection is much more common than previously thought in IBD patients with refractory disease (5-9). Cottone et al (6) reported finding CMV colitis in 19 out of 62 (30\%) Crohn's disease and ulcerative colitis patients with severe refractory colitis. Five patients went into remission after antiviral therapy. Papadakis 


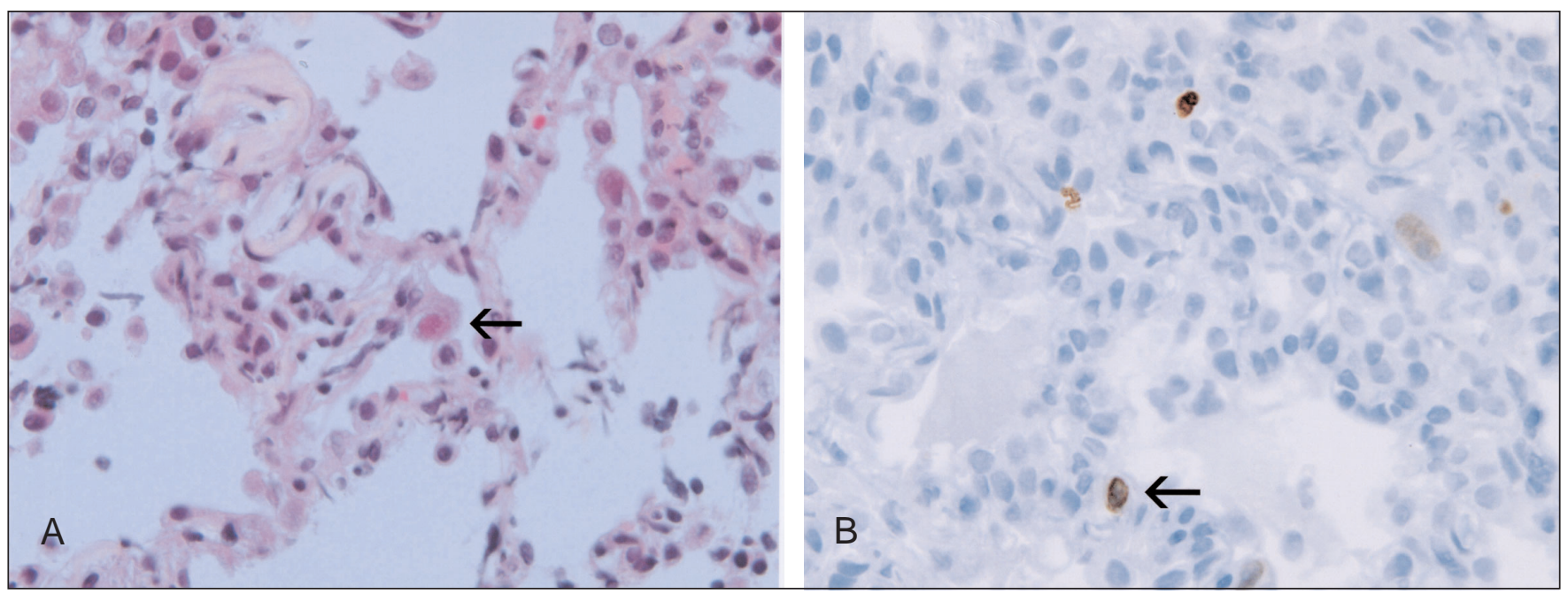

Figure 2) Histopathological evidence of cytomegalovirus infection in tissue obtained from transbronchial biopsy. A Classical cytopathic changes in nuclei of pneumocytes seen with cytomegalovirus. B Immunohistochemical staining confirming cytomegalovirus infection

et al (5) also reported eight patients with refractory IBD with colonic CMV, six of whom responded to antiviral therapy and withdrawal of immunosuppressants.

Several mechanisms appear to contribute to the risk of CMV infection in IBD, but drug treatment is clearly the most important. Azathioprine and 6-MP, when given alone, are sufficient to predispose to CMV infection or reactivation. They act by blocking DNA and RNA synthesis in proliferating lymphocytes (1) and disrupting natural killer cells, CD4 and CD8 lymphocytes, that play a fundamental role in preventing CMV infection and maintaining immunity (10). Some reports have suggested that steroids create a similar susceptibility to CMV infection as azathioprine and 6-MP (4), but the weight of evidence suggests that steroids alone do not convey the same risk (11). The greatest experience exists in the transplant literature, where steroids alone have been found to have little significant impact on the risk of CMV infection but do act synergistically with 6-MP and azathioprine to increase the risk of infection (11). Transplant studies also suggest that cyclosporine alone does not cause an increase in CMV infection but when combined with steroids has similar infection rates to azathioprine and steroids (12). Interestingly, one study has shown that patients with Crohn's disease have impaired natural killer cell function (13) suggesting disease activity may be an independent risk factor. Our case highlights that CMV infection can occur in patients with quiescent disease taking only 6-MP but, overall, it is likely that susceptibility is heightened when 6-MP or azathioprine are combined with steroids or other immunomodulators and/or disease activity is poorly controlled.

Our case illustrates the challenge of diagnosing the cause of pneumonia in the immunocompromised patient. A thorough history, physical examination and chest $\mathrm{x}$-ray are mandatory first steps and a systematic approach for obtaining specimens should be taken (14). Specific organisms can then be identified using either sputum Gram stain and culture, bronchoscopy with bronchial alveolar lavage and/or transbronchial biopsy or, rarely, open lung biopsy. Sputum for Gram stain is a logical first test given its ease and lack of invasiveness, but frequently it is contaminated with oropharyngeal organisms. However, identi- fication of certain fungi (Histoplasma, Coccidiodes imminitis), bacteria (Mycobacteria, Legionella) and viruses (respiratory syncitial virus, influenza) are indicative of infection. Direct fluorescent antibody testing for $P$ carinii pneumonia may also be performed on sputum specimens. Bronchoscopy is recommended as the next step and bronchoalveolar lavage is a safe technique for specimen collection in immunocompromised patients (15). Sensitivity may be as high as $80 \%$ to $90 \%$ in patients with diffuse pulmonary disease. Transbronchial biopsy mildly increases diagnostic yield (up to $90 \%$ ) but also carries a modestly increased risk of complications ( $8 \%$ to $9 \%$ of cases) (14). Open lung biopsy is reserved for difficult cases when other methods have failed. In this setting, sensitivity ranges from $60 \%$ to $80 \%$ but is associated with a higher morbidity and mortality than previously described tests (16).

A number of laboratory techniques are available to diagnose CMV infection in tissue specimens, but many have inherent limitations. A traditional approach, when the index of suspicion is high, is to culture the organism from body fluids using human fibroblasts as the culture medium (17). It may take many days, however, for cultures to be positive, as occurred in our case, and can even take three to four weeks (17). Shell vial culture, monoclonal antibodies and polymerase chain reaction are detection techniques that are much more rapid but are not routinely performed and are not available at many centres. With the shell vial technique, the specimen is centrifuged with fibroblasts, which assist the virus to become intracellular (17). Monoclonal antibodies to early CMV antigens are then applied to the shell vial culture. Results from this technique may be positive as early as $16 \mathrm{~h}$ after inoculation and sensitivity has been reported as high as $100 \%(18,19)$. Monoclonal antibodies to detect early CMV antigens in infected blood, urine and cerebrospinal fluid (18) have also been employed, but this technique is not widely available. Tanabe et al (20) reports $89 \%$ sensitivity for this test. Polymerase chain reaction has also been employed to detect genes encoding early antigens and can be very sensitive for detecting CMV DNA in many body fluids (21). Often, CMV infection has been suggested based on characteristic cytopathic changes found in biopsy specimens. Infected cells 
are large, round, and have ground glass-appearing cytoplasmic inclusions. Although serology has been proposed to distinguish between acute infection and chronic carriage of the virus, this technique is usually not helpful in immunocompromised patients $(19,22)$; indeed, our patient's serology was negative for both IgG and IgM.

In summary, our case discussion illustrates that CMV infection should be considered in IBD patients on immunosuppressants, even with quiescent disease. Diagnosis requires a systematic approach to obtaining tissue specimens and the appropriate use of available laboratory techniques.

\section{REFERENCES}

1. Pearson DC, May GR, Fick GH, Sutherland LR. Azathioprine and 6-Mercaptopurine in Crohn's disease. A meta-analysis. Ann Intern Med 1995;123:132-42.

2. Lennard L. The clinical pharmacology of 6-mercaptopurine. Eur J Clin Pharmacol 1992;43:329-39.

3. Baklien K, Brandtzaeg P. Comparative mapping of the local distribution of immunoglobulin-containing cells in ulcerative colitis and Crohn's disease of the colon. Clin Exp Immunol 1975;22:197-209.

4. Present DH, Meltzer SJ, Krumholz MP, Wolke A, Korelitz BI. 6-Mercaptopurine in the management of inflammatory bowel disease: Short- and long-term toxicity. Ann Intern Med 1989;111:641-9.

5. Papadakis KA, Tung JK, Binder SW, et al. Outcome of cytomegalovirus infections in patients with inflammatory bowel disease. Am J Gastroenterol 2001;96:2137-42.

6. Cottone M, Pietrosi G, Martorana G, et al. Prevalence of cytomegalovirus in severe refractory ulcerative and Crohn's colitis. Am J Gastroenterol 2001;96:773-5.

7. Orvar K, Murray J, Carmen G, Conklin J. Cytomegalovirus infection associated with onset of inflammatory bowel disease. Dig Dis Sci 1993;38:2307-10.

8. Vega R, Menacho M, Domenech E, et al. Cytomegalovirus infection in patients with inflammatory bowel disease. Am J Gastroenterol 1999;94:1053-6.

9. Kaufman HS, Kahn AC, Iacobuzio-Donahue C, Talamini MA, Lillemoe KD, Hamilton SR. Cytomegaloviral enterolcolitis: Clinical associations and outcome. Dis Colon Rectum 1999;42:24-30.
10. Hengel H, Koszinowski UH. Inhibition of MHC class I function by cytomegalovirus. In: Medveczky PG, Friedman H, Bendinelli M, eds. Herpesviruses and Immunity. New York: Plenum Press, 1998:247-64.

11. Rubin RH. Infection in the renal transplant patient. In: Rubin RH, Young LS, eds. Clinical Approach to Infection in the Compromised Host. New York: Plenum, 1981:553-605.

12. Dummer JS, Hardy A, Poorsatter A, et al. Early infections in kidney, heart, and liver transplant recipients on cyclosporine. Transplantation. 1983;36:259-67.

13. Ginsburg CH, Dambrauskas JT, Ault KA, Falchuk ZM. Impaired natural killer cell activity in patients with inflammatory bowel: Evidence for a qualitative defect. Gastroenterology 1983;85:846-51.

14. Dichter JR, Levine SJ, Shelhamer JH. Approach to the immunocompromised host with pulmonary symptoms. Hematol Oncol Clin North Am 1993; 7:887-912.

15. Verra F, Hmouda H, Rauss A, et al. Bronchoalveolar lavage in immunocompromised patients: Clinical and functional consequences. Chest 1992;101:1215-20.

16. Snyder C, Ramsay NK, McGlave PB, et al. Diagnostic open lung biopsy after bone marrow transplantation. J Pediatr Surg $1990 ; 25: 871-7$

17. Crumpacker CS. Cytomegaolvirus. In: Mandell GL, Bennett JE, Dolin R, eds. Principles and Practice of Infectious Diseases, 5th edn. Philadelphia: Churchhill Livingstone, 2000:1586-99.

18. Schuster EA, Bencke JS, Tegtmeier GE, et al. Monoclonal antibody for rapid laboratory detection of cytomegalovirus infections: Characterization and diagnostic application. Mayo Clin Proc 1985;60:577-85.

19. Murray BM, Amsterdam D, Gray V, et al. Monitoring and diagnosis of cytomegalovirus infection in renal transplantation. J Am Soc Nephrol 1997;8:1448-57.

20. Tanabe K, Tokumoto T, Ishikawa N, et al. Comparative study of cytomegalovirus antigenemia assay, polymerase chain reaction, serology, and shell vial assay in the early diagnosis and monitoring of CMV infection after renal transplantation. Transplantation 1997;64:1721-5.

21. Stanier P, Kitchen AD, Taylor DL, et al. Detection of human cytomegalovirus in peripheral mononuclear cells and urine samples using PCR. Mol Cell Probes 1992;6:51-8.

22. Bendiksen S, Van Ghelue M, Rekvig OP, Gutteberg T, Haga HJ, Moens U. A longitudinal study of human cytomegalovirus serology and viruria fails to detect active viral infection in 20 systemic lupus erythematosus patients. Lupus 2000;9:120-6. 


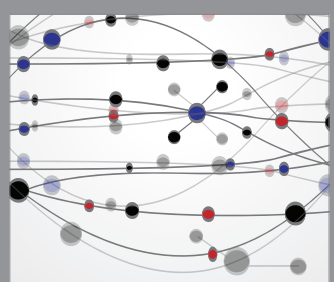

The Scientific World Journal
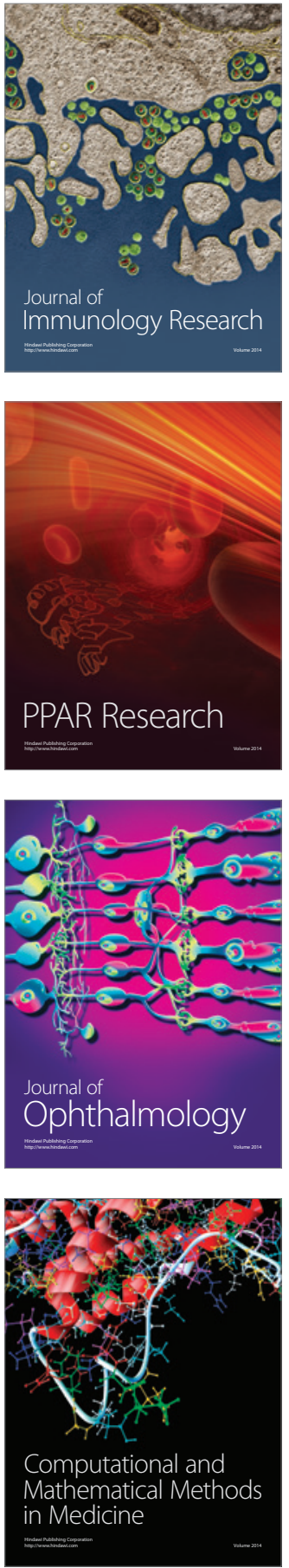

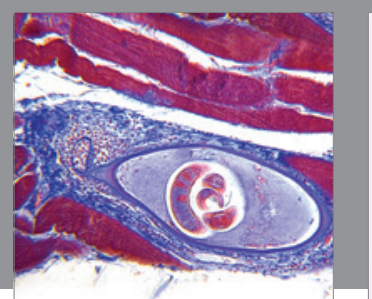

Gastroenterology Research and Practice

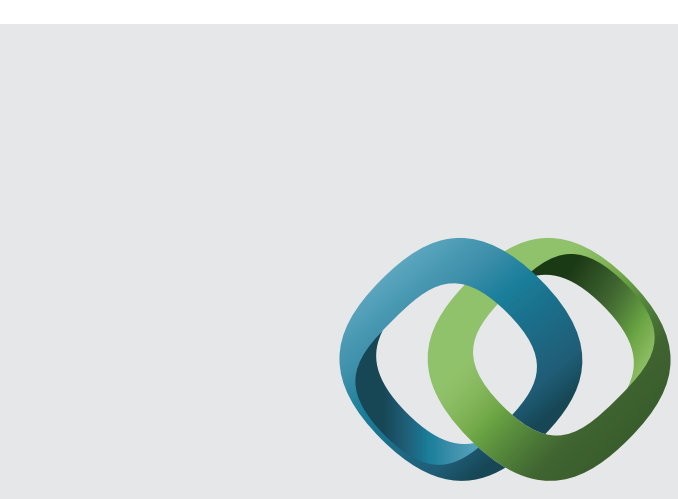

\section{Hindawi}

Submit your manuscripts at

http://www.hindawi.com
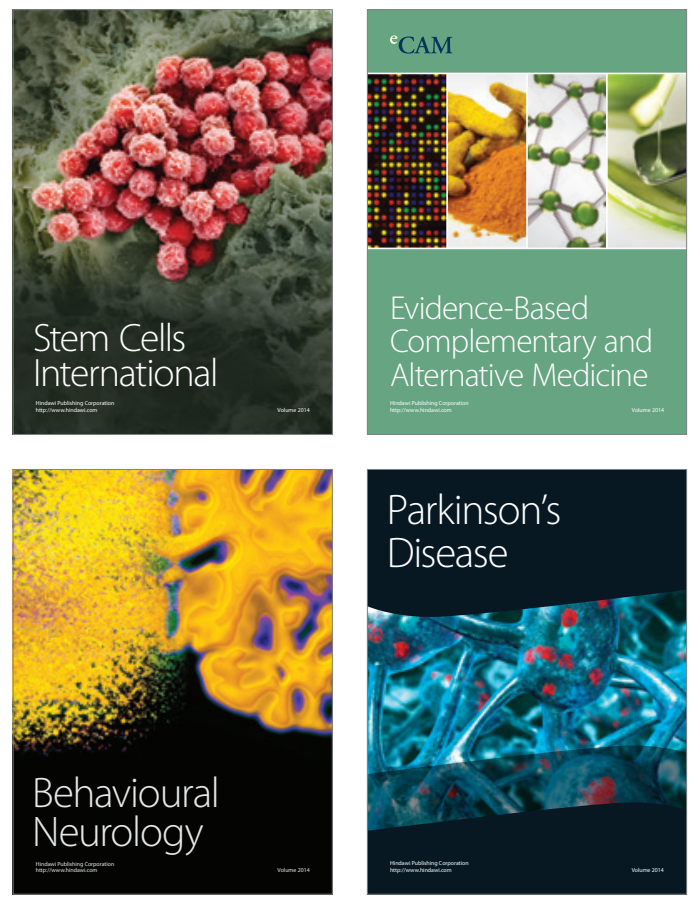
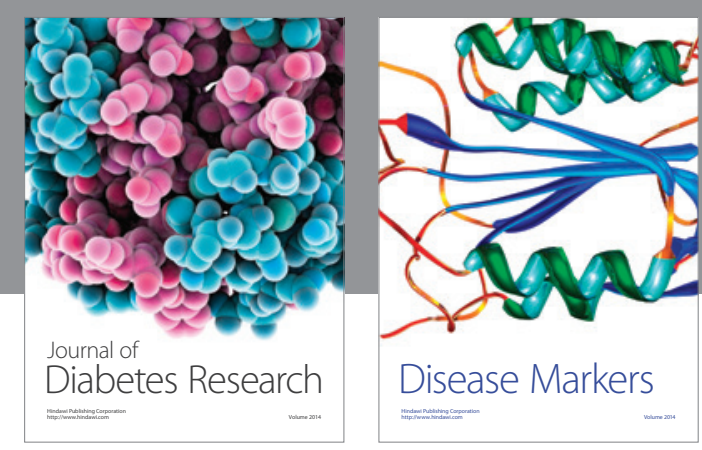

Disease Markers
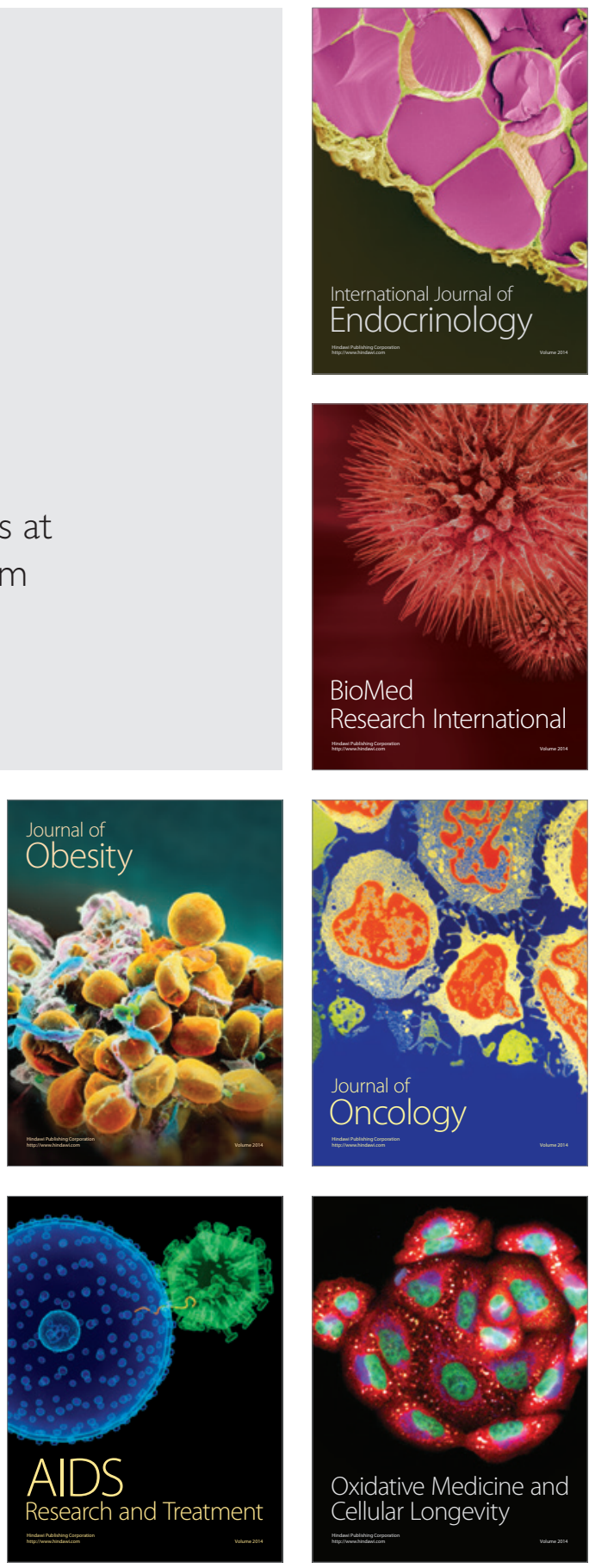